\title{
Distributional overlap rather than habitat differentiation characterizes co-occurrence of bivalves in intertidal soft sediment systems
}

\author{
Tanya J. Compton ${ }^{1,2,3, *}$, Tineke A. Troost ${ }^{1}$, Jaap van der Meer ${ }^{1}$, Casper Kraan $^{1,2}$, \\ Pieter J. C. Honkoop ${ }^{1}$, Danny I. $\operatorname{Rogers}^{4}{ }^{\text {, Grant B. Pearson }}{ }^{3}$, Petra de Goeij ${ }^{1}$, \\ Pierrick Bocher ${ }^{5}$, Marc S. S. Lavaleye ${ }^{1}$, Jutta Leyrer ${ }^{1,2}{ }^{,}$Mick G. Yates ${ }^{6}$, \\ Anne Dekinga ${ }^{1}$, Theunis Piersma ${ }^{1,2}$
}

\footnotetext{
${ }^{1}$ Department of Marine Ecology, Royal Netherlands Institute for Sea Research (NIOZ), PO Box 59, 1790 AB Den Burg, Texel, The Netherlands

${ }^{2}$ Centre for Ecological and Evolutionary Studies, University of Groningen, PO Box 14, 9750 AA Haren, The Netherlands

${ }^{3}$ Western Australian Department of Environment and Conservation (DEC), WA Wildlife Research Centre, PO Box 51, Wanneroo, Western Australia 6065, Australia

${ }^{4}$ Institute of Land, Water and Society, Charles Sturt University, PO Box 789, Albury, New South Wales 2640, Australia

${ }^{5}$ Centre de Recherche sur les Ecosystèmes Littoraux Anthropisés (CRELA), UMR 6217, Pôle science, CNRS-IFREMER-Université de la Rochelle, La Rochelle 17042, France

${ }^{6}$ Centre for Ecology and Hydrology - Monks Wood, Abbots Ripton, Huntingdon, Cambridgeshire PE28 2LS, UK
}

\begin{abstract}
Diverse species assemblages are often associated with a diversity of habitat structures. Sedimentary systems seem to be no exception, as within sedimentary systems benthic species diversity within a sample point appears to correlate with sediment grain size complexity. However, it remains to be shown whether total benthic species diversity relates to a system's sediment heterogeneity across multiple systems. In the present paper we examined whether bivalve diversity is associated with: (1) sediment heterogeneity across systems and (2) sediment grain size complexity within systems, at 9 temperate and tropical tidal flat systems. Although bivalve life-history strategies, like post-settlement habitat selection, might suggest that sediment heterogeneity should be important for bivalve species, bivalve diversity and sediment heterogeneity were not associated across systems. Interestingly, the association between total benthic diversity and sediment heterogeneity was also not significant, suggesting that changing species composition across systems does not account for the lack of a correlation between bivalve diversity and sediment heterogeneity. Instead of habitat differentiation, bivalve diversity within a sample point was highest in 'complex' fine-grained sediments and bivalve distributions showed a large degree of distributional overlap in all systems. The results of this study at both smaller and larger spatial scales suggest that coexistence between bivalve species in diverse tidal flats is not associated with increased sediment heterogeneity.
\end{abstract}

KEY WORDS: Sediment diversity - Banc d'Arguin - Roebuck Bay - The Wash • Wadden Sea • Mont Saint-Michel Bay · Marennes-Oléron Bay · Aiguillon Bay

\section{INTRODUCTION}

The habitat heterogeneity hypothesis (Simpson 1949, MacArthur \& Wilson 1967, Lack 1969) proposes that structurally diverse habitats harbour more species than less diverse habitats (Murdoch et al. 1972, August
1983). Although marine soft sediments are often considered to be vast and homogenous expanses of mud and sand (Hewitt et al. 2005), in reality they are complex environments where benthic species diversity is associated with structures on the sediment, e.g. shell debris material (Hewitt et al. 2005), seagrass beds 
(Orth et al. 1984, Edgar et al. 1994, Sheridan 1997, Boström et al. 2006, Honkoop et al. 2008) and sediment particle size diversity (Gray 1981, Whitlatch 1981, Etter \& Grassle 1992).

Within sedimentary systems, species richness within a sample point, i.e. point diversity, has been associated with sediment complexity (Whitlatch 1981, Etter \& Grassle 1992), e.g. annelid diversity (Whitlatch 1981) and total benthic diversity in the deep sea (Etter \& Grassle 1992) are correlated with fine-grained, 'complex' sediments. The association between species diversity and sediment grain size complexity has been suggested to reflect: (1) food diversity (Whitlatch 1981); (2) habitat complexity, as benthic species live on and within the sediment (Etter \& Grassle 1992); (3) sediment particle size fractionation by numerous benthic deposit feeders (Etter \& Grassle 1992); and (4) proximal factors like nutrient availability, hydrodynamics and microtopography (Etter \& Grassle 1992). Interestingly, although causation cannot be implied, it has been suggested that diverse benthic assemblages may create diverse sediment characteristics (Etter \& Grassle 1992).

Across multiple systems, sediment heterogeneity of a system might be associated with diverse species assemblages because habitat 'niches' should be reflected by sediment heterogeneity (Snelgrove \& Butman 1994) and benthic species can have distinct sediment preferences (Wolff 1973, van der Meer 1991, Ysebaert et al. 2002, Huxham \& Richards 2003, Thrush et al. 2003). Alternatively, the observation that species can co-occur in similar sediments, i.e. that point diversity is greatest in sediments of fine-grained particle complexity, suggests that sediment heterogeneity may be unimportant for species coexistence.

An important component of the benthic fauna, bivalves, was chosen to examine the correlation between diversity and sediment heterogeneity (Piersma et al. 1993, Ward \& Shumway 2004) because it is known that: (1) bivalve larvae can select their preferred sedimentary habitat during post-settlement (Gray 1967, Butman 1987, Wu \& Shin 1997, Bouma et al. 2001, Beukema \& Dekker 2003); (2) after settlement most adult bivalves have limited mobility making them dependent on their local sedimentary environment (Beesley et al. 1998); and (3) bivalve burial depth and speed (Stanley 1970, Edelaar 2000, de Goeij et al. 2001); as well as (4) feeding morphology (Drent et al. 2004, Ward \& Shumway 2004, Compton et al. 2008), are finely tuned to the sedimentary environment. Based on this knowledge of bivalve life-history strategies, it was expected that bivalve diversity should be associated with a system's sediment heterogeneity.

In the present study we examined whether bivalve diversity is associated with: (1) sediment heterogeneity across systems and (2) sediment grain size complexity within systems, at 6 temperate and 3 tropical tidal flat systems (north-western Europe: German and Dutch parts of the Wadden Sea, The Wash [UK], Mont SaintMichel Bay, Marennes-Oléron Bay and Aiguillon Bay [France]; eastern Atlantic: Banc d'Arguin [Mauritania]; Indo-Pacific: Eighty-Mile Beach and Roebuck Bay [Australia]). The association between total benthic diversity and sediment heterogeneity was also examined to determine whether changing species composition across systems was associated with sediment heterogeneity.

\section{MATERIALS AND METHODS}

Sampling sites. Descriptions of the tidal flat systems examined here are given in Table 1; additional information can be found in Wolff \& Smit (1990), Pepping et al. (1999), Honkoop et al. (2006), van Gils et al. (2006), Bocher et al. (2007), Kraan et al. (2007), Honkoop et al. (2008). All systems, except the Banc d'Arguin, were sampled using a grid mapping approach, where a grid of points was sampled over an area representative of each tidal flat (see Table 1 and Appendix 1 available at www.int-res.com/articles/suppl/m373p025_app.pdf, maps were made in ArcView 3.2a). In Europe, sample points were positioned $250 \mathrm{~m}$ apart, in Australia, $200 \mathrm{~m}$ apart. All sample points were identified using handheld global positioning system receivers (Garmin Corporation). In the Banc d'Arguin tidal flat system, paired sampling was completed at 13 bare tidal flat and 13 seagrass (Zostera noltii) sites (Honkoop et al. 2008).

The tidal flat systems in the present study can be considered representative of open offshore tidal flat systems with high mollusc densities (see aforementioned references). All systems are sites where a molluscivore migrant shorebird, the red knot Calidris canutus, occurs (Piersma et al. 1993, Bocher et al. 2007). Obvious vegetation features are not apparent in most systems (see Pepping et al. 1999, Honkoop et al. 2006, van Gils et al. 2006, Bocher et al. 2007), except at the Banc d'Arguin, which is covered largely by seagrass (79 of $491 \mathrm{~km}^{2}$ is not covered by seagrass; Wolff \& Smit 1990) and Roebuck Bay (Pepping et al. 1999). Roebuck Bay is the only system with a large mangrove fringe (Pepping et al. 1999); Eighty-Mile Beach and the Banc d'Arguin only have a few hectares of mangroves (Wolff \& Smit 1990, Honkoop et al. 2006).

Benthos and sediment sampling. A single benthic core (surface area of $0.02 \mathrm{~m}^{2}$ ) was taken to a depth of $20 \mathrm{~cm}$ at the individual sample points in Europe and Australia. The sampling protocol differed at the Banc d'Arguin; 3 benthic cores $\left(0.18 \mathrm{~m}^{2}\right.$ to $30 \mathrm{~cm}$ deep) were 


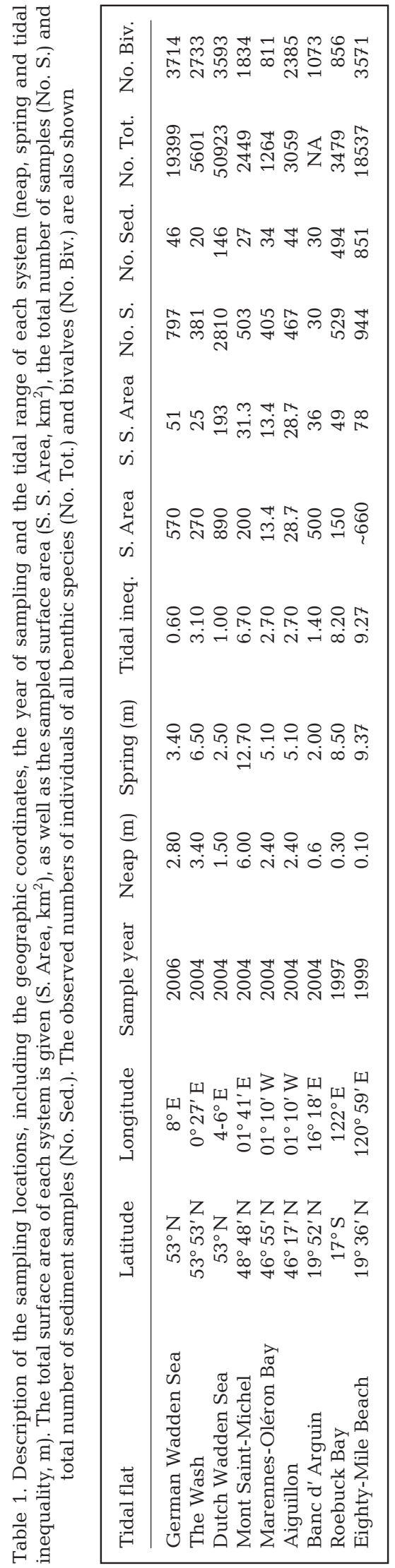

taken at each sample point in both tidal flat and seagrass areas. At all sites a $1 \mathrm{~mm}$ meshed sieve was used to separate the benthic species from the sediment. Following sieving, benthic animals were either immediately identified and counted or stored for later identification. At the Banc d'Arguin, only bivalve species were identified. In the French systems, the total diversity may be slightly underestimated, as only worms and molluscs were identified to species level. Other species contributed only a minor component of the total species community (Bocher pers. obs.). All bivalve species names and their authorities are documented in Appendix 2 (available at www.int-res.com/articles/ suppl/m373p025_app.pdf).

In Europe 1 sediment core $\left(0.0002 \mathrm{~m}^{2}, \sim 8 \mathrm{~cm}\right.$ deep) was taken for every 16 benthic cores (1 km intervals) across the entire sample grid (see Appendix 1, large dots represent sediment samples taken). This approach was chosen to obtain an overview of the sediment heterogeneity of the total system. At the Banc d'Arguin 2 sediment samples were taken (59 mm diameter core, $\sim 5$ mm deep) at each sample point (Honkoop et al. 2008, also see Appendix 1). At Roebuck Bay and Eighty-Mile Beach sediment samples were taken at the majority of sample points using a core of $0.002 \mathrm{~m}^{2}$ to $\sim 8 \mathrm{~cm}$ deep (see Appendix 1).

European and Banc d'Arguin sediment grain sizes were analysed using a particle size analyzer (Beckman Coulter Model LS 230), see also Honkoop et al. (2008) for methods. Sediment grain sizes from Roebuck Bay and Eighty-Mile Beach were analysed using a wet-sieving method (see Honkoop et al. 2006, Pepping et al. 1999). Median grain size values and the standard deviation around the median grain size were used to compare the systems in this study because median grain size estimates were comparable between the 2 different methods, whereas silt values were not (Konert \& van den Bergh 1997, Buurman et al. 2001).

In the European systems, median grain size values at the sample points where sediment was not sampled were estimated with an inverse distance-weighting interpolation (Fortin \& Dale 2005) in ArcGIS. An inverse distance-weighting interpolation calculates the missing sediment values from the surrounding measured values and does not extrapolate beyond the measured values. The few missing median grain size values at Roebuck Bay were estimated by averaging the median grain size values from surrounding sample points. We chose to include interpolated values in the analysis of point diversity versus sediment grain size complexity as they gave a good representation of the overall heterogeneity of each system and enabled use of all sampled benthic points. In addition, the results presented in the present paper did not change 
when interpolated values were excluded from the analyses.

Diversity and sediment heterogeneity analysis. The sediment heterogeneity of each system was determined from the: (1) interquartile range of median grain size values, (2) interquartile range of standard deviation values and (3) the total sediment range (maximum to minimum value of median grain size). Interquartile ranges (IQR) are unbiased estimators that give a measure of statistical dispersion between the first and third quartile, representing $50 \%$ of the data. Whiskers represent values that fall within $\pm 1.5 \times \mathrm{IQR}$, and outliers represent values that fall outside of the range of the whiskers (here indicated as dots).

Species accumulation curves were drawn using the 'exact' function from the package Vegan in the R interface (Oksanen 2007). The exact function finds the expected richness and variance of the species-accumulation curve, as approximated by a semi-log curve (Ugland et al. 2003, Colwell et al. 2004).

To normalize observed species richness at each local system for sampling effort (Palmer 1990, Colwell \& Coddington 1994), species richness was estimated with a first-order jackknife method, separately for each system, using the Specpool function from the package Vegan in the R interface (Smith \& van Belle 1984, Oksanen 2007). The first-order jackknife method calculates species frequencies from the collection of sampled points using this calculation:

$$
S_{\mathrm{p}}=S_{\mathrm{o}}+\mathrm{a}_{1}[(N-1) / N]
$$

where $S_{\mathrm{p}}$ is the extrapolated richness in a species pool, $S_{\mathrm{o}}$ is the observed number of species in the total collection of sampled grid-points, $a_{1}$ is the number of species occurring at 1 sample point and $N$ is the total number of sample points in a system (Oksanen 2007). Shannon's index (Pielou 1966, 1975) was also calculated for each system using the formula:

$$
H^{\prime}=-\Sigma_{i} p_{i} \log _{b} p_{i}
$$

where $p_{i}$ is the proportional abundance of species $i$ and $b$ is the base of the logarithm. Shannon's index is high either when there are a high number of unique species or when species share similar abundances within the community.

Another measure of diversity, taxonomic distinctness $\left(\Delta^{+}\right)$, was also calculated. Taxonomic distinctness is a measure of how diverse a community is in terms of its taxonomy (Clarke \& Warwick 1998). It is calculated from:

$$
\Delta^{+}=\left[\Sigma \Sigma_{i<j} \omega_{i j}\right] /[s(s-1) / 2]
$$

where $s$ is the number of species present, the double summation is over $\{i=1, \ldots ., j=1, \ldots S$, such that $i<j\}$ and $\omega$ is the 'distinctness weight' given to the path length linking species $i$ and $j$ in the hierarchical classification (Clarke \& Warwick 1998). The taxonomic levels used in the present study are species, genus, family, superfamily, order and subclass based on the taxonomic phylogeny of bivalves as depicted in the 'southern synthesis' (Beesley et al. 1998). Calculations of $\Delta^{+}$ assumed equal step lengths between the taxonomic levels.

Pearson correlations were used to examine whether the extrapolated species richness, Shannon index and taxonomic distinctness were correlated with sediment heterogeneity, i.e. interquartile range and total range. Pearson correlations were calculated for all systems together, and for the European systems.

Diversity and sediment grain size analysis. To examine whether the diversity of bivalve species per sample point (Whittaker 1972, Ricklefs \& Schluter 1993) was correlated with median grain size and responded similarly between systems, we regressed bivalve point diversity $(y)$ on median grain size $(x)$ using the following model:

$$
y=\exp \left(\alpha+\alpha_{i}+\beta x+\beta_{i} x\right)
$$

where the index $i$ refers to the different tidal flat systems. A Poisson regression, i.e. a class of generalized linear models (McCullagh \& Nelder 1989), was used because alpha diversity is a type of count data. Checks of the resulting deviances showed there was no significant overdispersion, i.e. that the residual scaled deviance was roughly equal to the residual degrees of freedom (Crawley 2005). To obtain the best fitting model, we performed a standard model-selection procedure. One by one, model terms whose removal led to the largest decrease in Akaikes information criterion (AIC, a penalised log-likelihood; Crawley 2005) were taken out of the model. Note that all terms in the model, including the interaction between median grain size and system, were significant (Null AIC $=16736$, model with no interaction term, $\mathrm{AIC}=15782$ and complete model from Eq. (3), AIC = 15798), such that the optimal model (after model selection) was equal to the original model. Although the height of the intercept in the case of the Banc d'Arguin is not comparable to those of the other systems, as the surface area per sample point was greater than those of the other studies, the regression slope should be comparable. We have thus included this system in the analysis.

To examine how bivalve species were distributed relative to each other and the sediment heterogeneity of each system, we depicted the occurrence of each bivalve species as an interquartile range (IQR) with respect to median grain size (including the interpolated values). 


\section{RESULTS}

\section{Diversity and sediment heterogeneity}

Sampled bivalve diversity reached an asymptote at all systems (Fig. 1). The species accumulation curves of total benthic diversity tended towards an asymptote at all tidal flat systems except Roebuck Bay, Eighty-Mile Beach, Mont Saint-Michel Bay and Marennes-Oléron Bay (Fig. 1). The European tidal flats had relatively low levels of estimated species richness (bivalves: 8 to 11 , total: 12 to 49 ) compared to the tropical tidal flats (bivalves: 20, 25 and 34 species, total: 112, 163; also see Table 2). The Shannon-Wiener index and the taxonomic distinctness index showed no differences between the tropical and temperate systems (see Table 2). Aside from these results, we also observed that species richness at the Banc d'Arguin differed between seagrass (ESR 20) and bare patches (ESR 14).

The interquartile range in median grain sizes was greatest at the Banc d'Arguin (IQR: $107 \mu \mathrm{m}$ ), Roebuck Bay and the Wash (both IQR: $~ 70 \mu \mathrm{m}$ ). Aiguillon Bay and Eighty-Mile Beach had the smallest range in median grain size values (IQR: 2 and $8 \mu \mathrm{m}$; see Table 2, Fig. 2). The greatest range in the standard deviation of sediments was observed at Mont Saint-Michel Bay (SD: $114 \mu \mathrm{m})$ and Marennes-Oléron Bay (SD: $171 \mu \mathrm{m}$; see Table 2, Fig. 2). For all 9 systems, bivalve diversity and total benthic diversity were not correlated with any of the 3 measures of sediment heterogeneity (IQR of median grain size, IQR of standard deviation of median grain size and the
German Wadden Sea

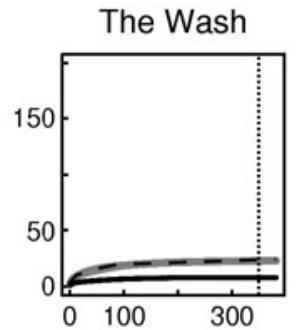

Mont Saint-Michel Bay Marennes-Oléron Bay
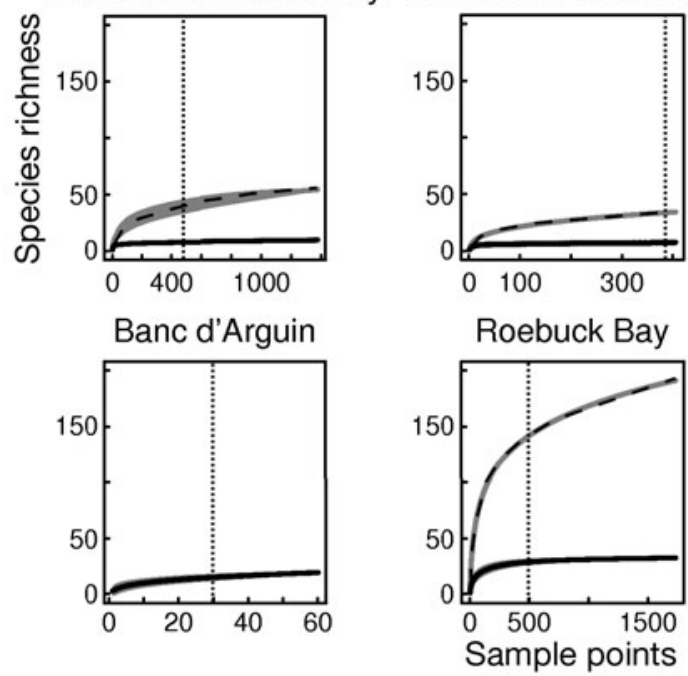
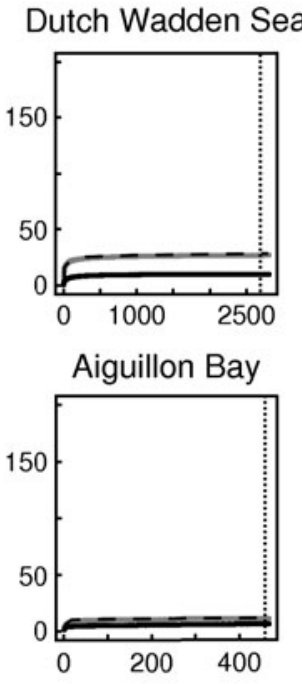

Eighty-Mile Beach

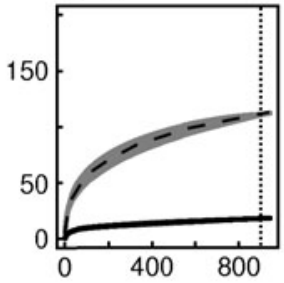

Fig. 1. Species accumulation lines for bivalve diversity (black line) and total benthic diversity (grey line) in each system. The standard deviations from random permutations of the data are shown as the shaded widths around each line. Vertical lines indicate the number of samples taken in each system

total range of median grain sizes; see Table 3, Fig. 3). The Shannon-Wiener index and the taxonomic distinctness index (in bivalves) were also not correlated with sediment heterogeneity (Table 3 ). The association between bivalve diversity or total benthic diversity and sediment heterogeneity was also non-significant across the 6 European systems (Table 3).

Table 2. Observed (OR) and expected species richness (jackknife calculation, ER), Shannon-Wiener Index of diversity $\left(H^{\prime}\right)$ and taxonomic distinctness (Delta) of both total bivalve diversity and total benthic diversity from each system. In addition, the interquartile range (IQR), the total range (TR) and the IQR of the standard deviation (SD) of the measured median grain sizes (MGS) are given

\begin{tabular}{|c|c|c|c|c|c|c|c|c|c|c|}
\hline \multirow[t]{2}{*}{ Tidal flat } & \multicolumn{4}{|c|}{ Bivalve diversity } & \multicolumn{3}{|c|}{ Total benthic diversity } & \multirow{2}{*}{$\begin{array}{l}\text { IQR of } \\
\text { MGS }\end{array}$} & \multirow{2}{*}{$\begin{array}{l}\text { TR of } \\
\text { MGS }\end{array}$} & \multirow{2}{*}{$\begin{array}{c}\text { IQR of } \\
\text { SD }\end{array}$} \\
\hline & OR & ER & $H^{\prime}$ & Delta & OR & ER & $H^{\prime}$ & & & \\
\hline German Wadden Sea & 7 & 10 & 0.66 & 4.48 & 28 & 32 & 1.72 & 30 & 146 & 18 \\
\hline The Wash & 8 & 9 & 1.04 & 4.46 & 23 & 25 & 1.65 & 83 & 272 & 24 \\
\hline Dutch Wadden Sea & 10 & 11 & 3.51 & 4.73 & 27 & 28 & 2.30 & 42 & 207 & 17 \\
\hline Mont Saint-Michel & 7 & 7 & 0.94 & 4.24 & 39 & 49 & 1.89 & 61 & 389 & 114 \\
\hline Marennes-Oléron Bay & 7 & 8 & 1.33 & 4.86 & 34 & 45 & 2.30 & 58 & 418 & 171 \\
\hline Aiguillon & 6 & 7 & 1.25 & 3.70 & 11 & 12 & 1.77 & 2 & 33 & 19 \\
\hline Banc d'Arguin & 16 & 20 & 1.48 & 4.77 & & & & 106 & 311 & 30 \\
\hline Roebuck Bay & 32 & 34 & 2.62 & 4.36 & 163 & 197 & 2.22 & 72 & 277 & 29 \\
\hline Eighty-Mile Beach & 18 & 25 & 1.02 & 3.94 & 112 & 140 & 2.82 & 9 & 393 & 22 \\
\hline
\end{tabular}



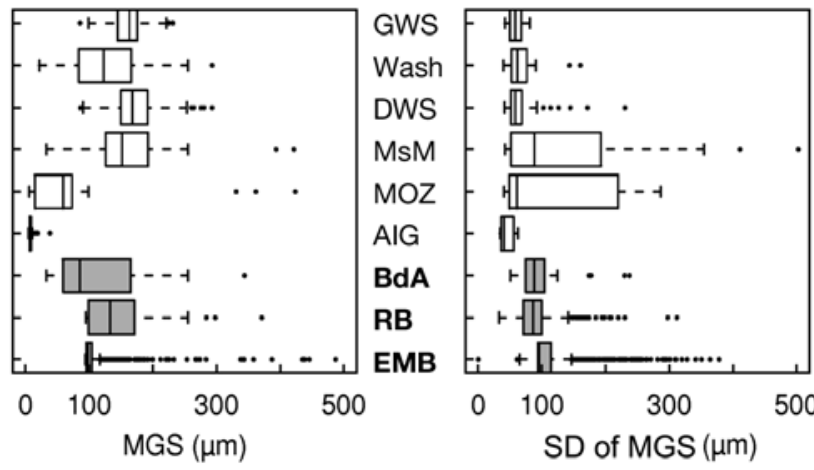

Fig. 2. Box and whisker plots representing sediment heterogeneity within each tidal flat system. Heterogeneity is represented as: (1) the measured median grain size (MGS) values and (2) the standard deviation (SD) of grain size values within a core. In the boxes the vertical lines indicate the median of the MGS and SD values, boxes represent the interquartile ranges (IQR), i.e. $50 \%$ of the measured values; dashed lines represent $1.5 \times \mathrm{IQR}_{\text {; }}$ dots represent outlying values. GWS: German Wadden Sea; Wash: The Wash; DWS: Dutch Wadden Sea; MsM: Mont Saint-Michel Bay; MOZ: Marennes-Oléron Bay; AIG: Aiguillon Bay; BdA: Banc d'Arguin; RB: Roebuck Bay; EMB: Eighty-Mile Beach. The tropical systems are shaded in grey, and their abbreviations are in bold

\section{Diversity and sediment grain size}

The Poisson regression between bivalve point diversity and median grain size showed a significant negative correlation with median grain size $\left(\beta_{1}=-0.008\right.$, $z$-value $=-7.2, \mathrm{p}<0.001$; Table 4 , Fig. 4). In addition, Roebuck Bay showed a significantly higher level of point diversity relative to all other systems except the German Wadden Sea, the Wash and the Banc d'Arguin (Table 4, Fig. 4). The significant interaction term between median grain size and system in the complete model showed that the response curve of predicted bivalve point diversity and median grain size was system dependent. Specifically, the predicted bivalve point diversity response with median grain size $\left(\beta_{i} x\right)$ at Mont-Saint Michel Bay, Banc d'Arguin and Eighty-Mile Beach were significantly different from Roebuck Bay $(\mathrm{MsM} z$-value $=3.4, \mathrm{p}<0.001, \mathrm{EMB} z-$ value $=3.9, \mathrm{p}<0.001$ and Mauritania $z-$ value $=4.0, \mathrm{p}<0.001 ;$ Table 4). Although the predicted point diversity at Aiguillon Bay appeared to show a positive relationship with median grain size, this correlation was not significantly different to the negative correlation observed at Roebuck Bay (z-value

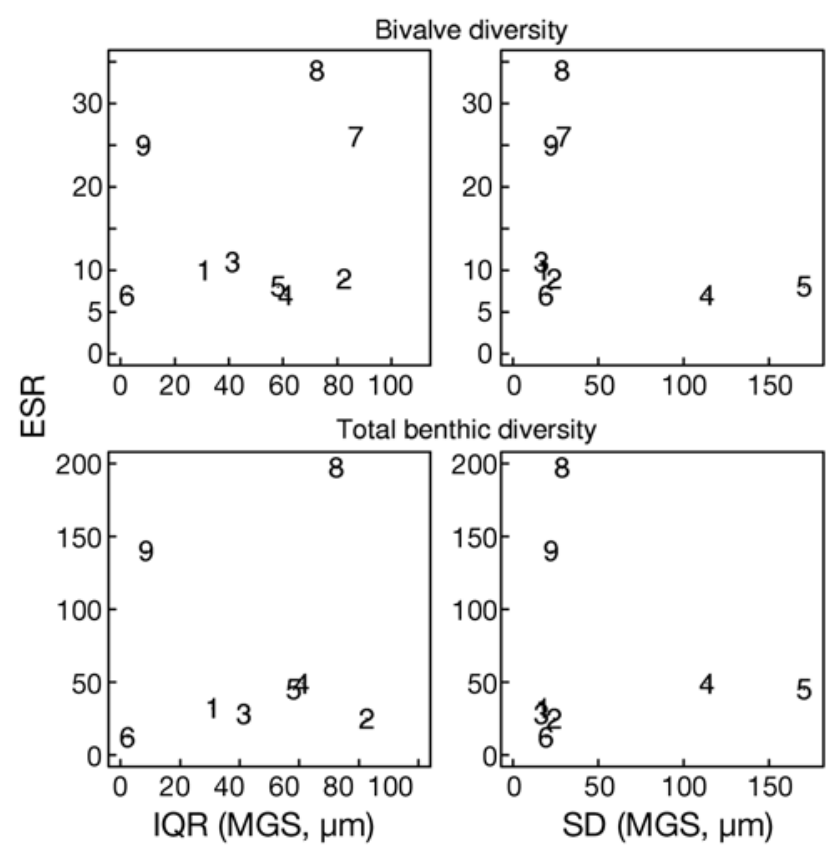

Fig. 3. Sediment heterogeneity (difference between the third and first quartile, IQR) and the standard deviation of the sediments (difference between the third and first quartile, IQR) plotted against estimated species richness, ESR. No correlation exists. 1: German Wadden Sea; 2: Dutch Wadden Sea; 3: The Wash; 4: Mont Saint-Michel Bay; 5: Marennes-Oléron Bay; 6: Aiguillon Bay; 7: Banc d'Arguin; 8: Roebuck Bay; 9: Eighty-Mile Beach. Note that these graphs were generated with the measured median grain size values alone

Table 3. Correlations between bivalve diversity or total benthic diversity (ESR: estimated species richness; $H^{\prime}$ : Shannon-Wiener index of diversity; Delta: taxonomic distinctness) and sediment heterogeneity. These were not significant (Pearson correlations, cor) for most of the 9 systems and most of the 6 European systems (eur). Other abbreviations, see Table 2

\begin{tabular}{|c|c|c|c|c|c|c|c|c|}
\hline & \multicolumn{4}{|c|}{ Bivalve diversity } & \multicolumn{4}{|c|}{ — Total benthic diversity } \\
\hline & $t$ & df & $\mathrm{p}$ & cor & $t$ & df & $\mathrm{p}$ & cor \\
\hline \multicolumn{9}{|l|}{ ESR with: } \\
\hline IQR & 1.17 & 7 & 0.28 & 0.41 & 0.58 & 6.00 & 0.58 & 0.23 \\
\hline IQR (eur) & 1.12 & 4 & 0.32 & 0.49 & 1.49 & 4.00 & 0.21 & 0.59 \\
\hline TR & 0.75 & 7 & 0.48 & 0.27 & 1.07 & 6.00 & 0.32 & 0.40 \\
\hline TR (eur) & -0.17 & 4 & 0.87 & -0.09 & 4.36 & 4.00 & 0.01 & 0.91 \\
\hline $\mathrm{SD}$ & -0.98 & 7 & 0.35 & -0.34 & -0.31 & 6.00 & 0.77 & -0.12 \\
\hline SD (eur) & -1.13 & 4 & 0.32 & -0.49 & 2.67 & 4.00 & 0.06 & 0.80 \\
\hline \multicolumn{9}{|l|}{$H^{\prime}$ with: } \\
\hline IQR & 1.59 & 7.00 & 0.16 & 0.52 & 0.26 & 6.00 & 0.80 & 0.11 \\
\hline IQR (eur) & 1.61 & 4.00 & 0.18 & 0.63 & -0.13 & 0.97 & 0.08 & 0.76 \\
\hline TR & -0.58 & 7.00 & 0.58 & -0.21 & 2.28 & 6.00 & 0.06 & 0.68 \\
\hline TR (eur) & -0.44 & 4.00 & 0.68 & -0.21 & 1.73 & 4.00 & 0.15 & 0.65 \\
\hline $\mathrm{SD}$ & -0.58 & 7.00 & 0.58 & -0.21 & 0.25 & 6.00 & 0.81 & 0.10 \\
\hline SD (eur) & -0.44 & 4.00 & 0.68 & -0.21 & 1.16 & 4.00 & 0.31 & 0.50 \\
\hline \multicolumn{9}{|l|}{ Delta with: } \\
\hline IQR & 3.26 & 7 & 0.01 & 0.78 & & & & \\
\hline IQR (eur) & 3.13 & 4 & 0.04 & 0.84 & & & & \\
\hline TR & 1.13 & 7 & 0.29 & 0.39 & & & & \\
\hline TR (eur) & 1.75 & 4 & 0.15 & 0.66 & & & & \\
\hline SD & 0.95 & 7 & 0.37 & 0.34 & & & & \\
\hline SD (eur) & 0.81 & 4 & 0.46 & 0.38 & & & & \\
\hline
\end{tabular}


Table 4. Results from the Poisson regression model which examined the relationship between the number of species per sample point and median grain size in each system (MGS), using Roebuck Bay as the reference system for comparison between the systems (see Eq. 4 in 'Materials and methods'). Systems are coded as in Fig. 2. The regression coefficient $(\alpha)$, the $z$-value and $p$-value are shown

\begin{tabular}{|lccc|}
\hline & Coefficient & z-value & $\operatorname{Pr}(>|z|)$ \\
\hline$\alpha$ & 1.3806 & 9.8 & $<0.001$ \\
$\alpha \times$ GWS & -0.4493 & -1.7 & 0.09 \\
$\alpha \times$ Wash & -0.4304 & -2.3 & 0.02 \\
$\alpha \times$ DWS & -1.1165 & -5.7 & $<0.001$ \\
$\alpha \times$ MsM & -1.0639 & -4.9 & $<0.001$ \\
$\alpha \times$ MOZ & -1.314 & -8.4 & $<0.001$ \\
$\alpha \times$ AIG & -1.1648 & -6.5 & $<0.001$ \\
$\alpha \times$ Maur & 0.073 & 0.3 & 0.74 \\
$\alpha \times$ EMB & -1.7682 & -8.7 & $<0.001$ \\
MGS & -0.0077 & -7.2 & $<0.001$ \\
MGS $\times$ GWS & 0.0012 & 0.7 & 0.48 \\
MGS $\times$ Wash & 0.0013 & 0.9 & 0.38 \\
MGS $\times$ DWS & 0.0032 & 2.3 & 0.02 \\
MGS $\times$ MsM & 0.005 & 3.4 & $<0.001$ \\
MGS $\times$ MOZ & 0.0028 & 1.8 & 0.07 \\
MGS $\times$ AIG & 0.0217 & 1.8 & 0.07 \\
MGS $\times$ Maur & 0.0067 & 4.0 & $<0.001$ \\
MGS $\times$ EMB & 0.0067 & 3.9 & $<0.001$ \\
\hline
\end{tabular}

$=1.8, \mathrm{p}=0.07$ ). Furthermore, boxplots of occurrence also showed distributional overlap in bivalve species in these 9 systems (Figs. 5 \& 6). Distributional overlap was most apparent in the diverse tropical systems of Roebuck Bay and the Banc d'Arguin (Fig. 6).

\section{DISCUSSION}

Consistent with the latitudinal diversity gradient observed at other estuarine and coastal tidal flats (Sanders 1968, Attrill et al. 2001), bivalve diversity was highest at the 3 tropical and lowest at the 6 temperate tidal flats. Tropical bivalve species richness was not associated with greater sediment heterogeneity, as (1) the sediment heterogeneity in the tropical systems was no greater than in temperate systems and (2) there was no significant correlation between estimated bivalve diversity and sediment heterogeneity across all 9 tidal flat systems nor across the 6 European systems. Total benthic diversity and sediment heterogeneity were also not correlated across systems. This shows that a change in species composition across systems, i.e. other phyla, does not account for the lack of a correlation between bivalve diversity and sediment heterogeneity in this study.

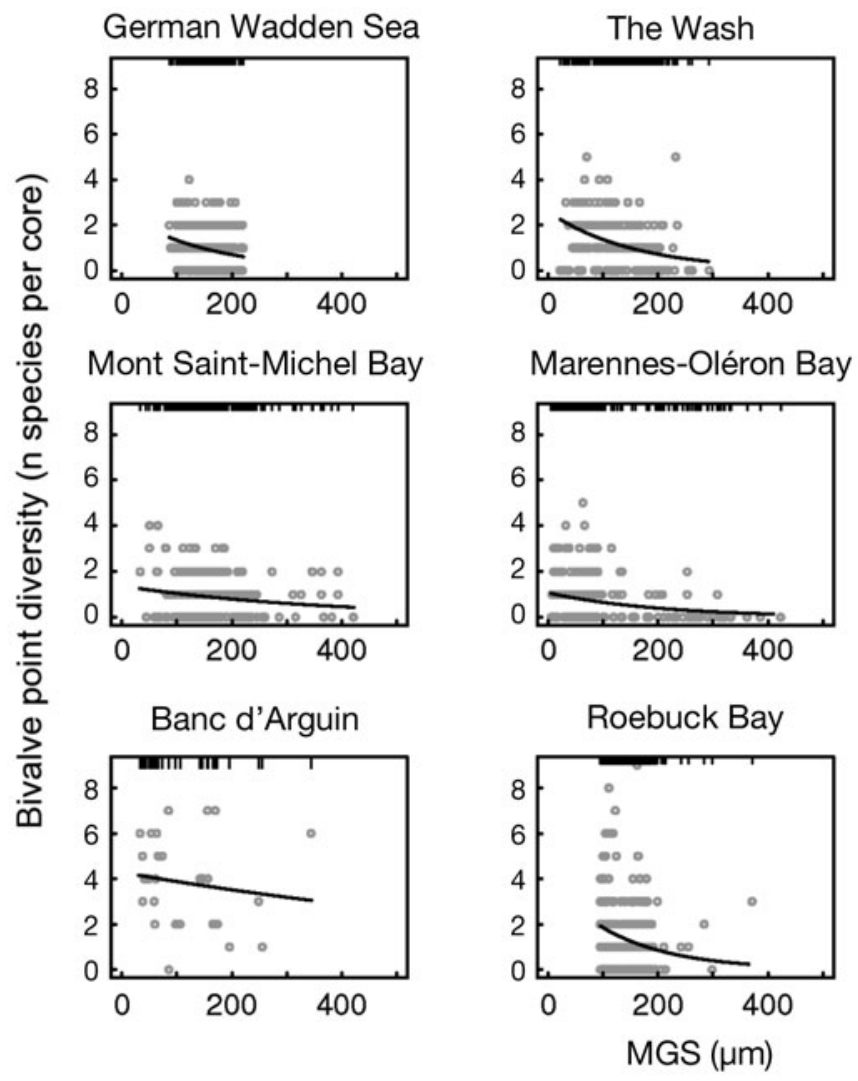

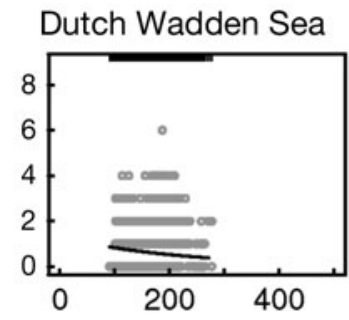

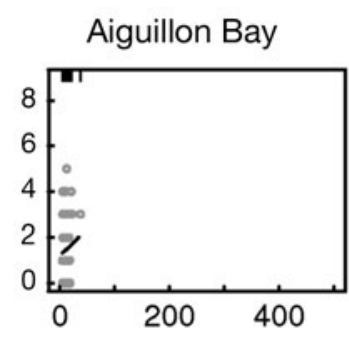

Eighty-Mile Beach

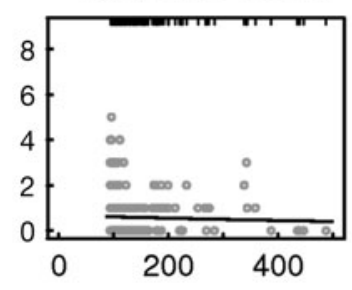

Fig. 4. Negative correlations between bivalve point diversity, at a sample point, and median grain size values within a system, as estimated by a Poisson regression analysis (solid lines). The measured species count data are given as grey circles. The rug plot (line intervals on top of the graph) indicates the median grain size values measured in each system 


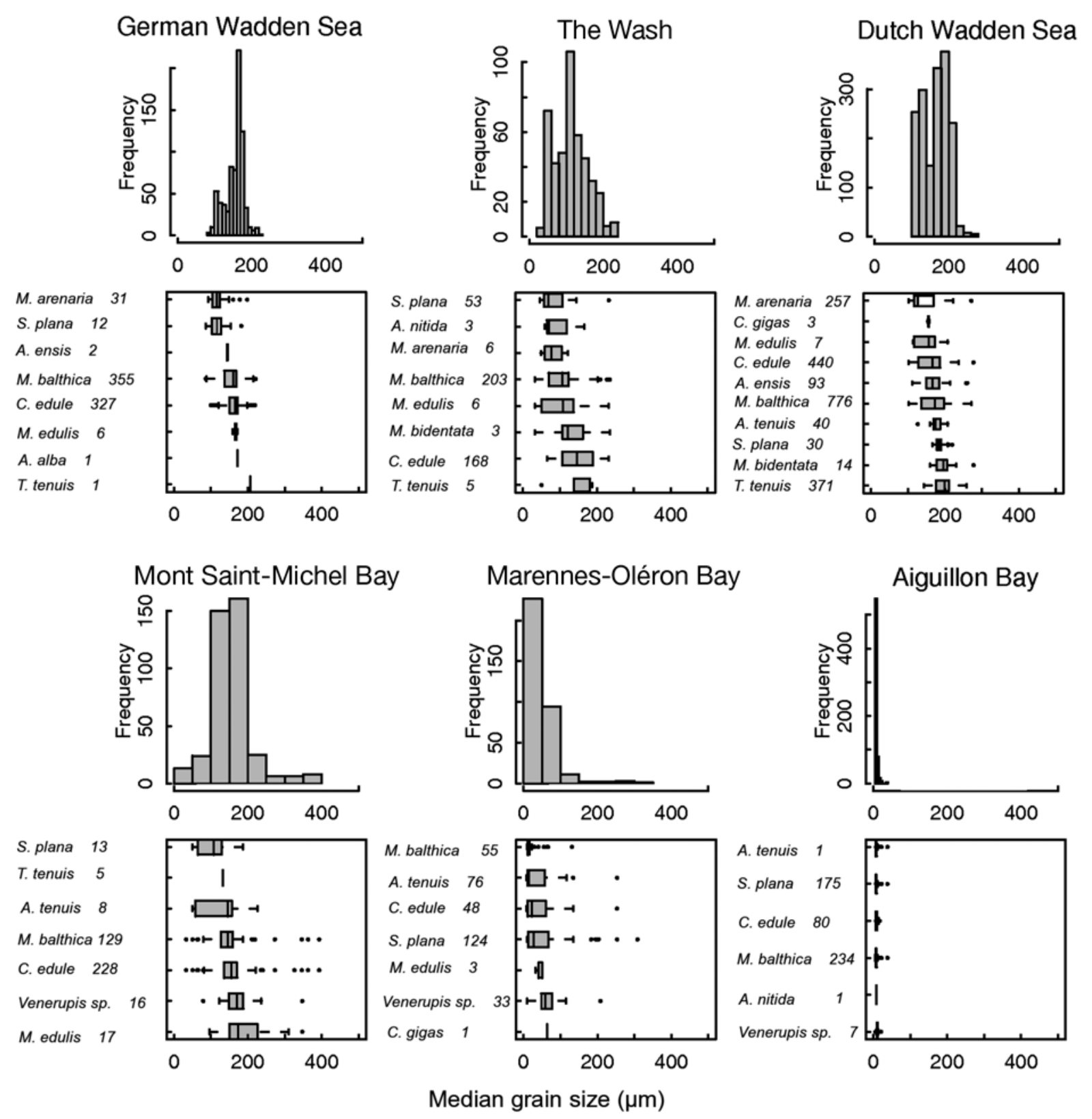

Fig. 5. Ranked boxplots of bivalve species distributions (presence data only) in the temperate European intertidal systems, including benthic sample points from both measured and interpolated median grain size values. The name of the species and number of occurrences measured per species are shown next to each boxplot. The histograms above the boxplots represent the frequency of median grain size values occurring in each system. Full names of the species are given in Appendix 2 (www.int-res.com/ articles/suppl/m373p025_app.pdf)

Similar to previous studies (Whitlatch 1981, Etter \& Grassle 1992), bivalve diversity within a sample point was greatest in fine-grained sediments in most systems. The exception appeared to be Aiguillon Bay, a system dominated by a narrow range of muddy sediments. High point diversity in finer-grained sediments suggests species are either sharing distributional overlap or live separated in space, but within similar finegrained sediments. This correlation did not hold for point diversity of the total benthic assemblage (Compton data not shown), suggesting that this result is unique to bivalve point diversity. Interestingly, in a separate group, amphipods, it was found that point diversity was positively associated with coarser sediment grain sizes (Biernbaum 1979). Perhaps the association between point diversity and sediment is group dependent. The number of species found in a core appeared to be highest at Roebuck Bay, the German 

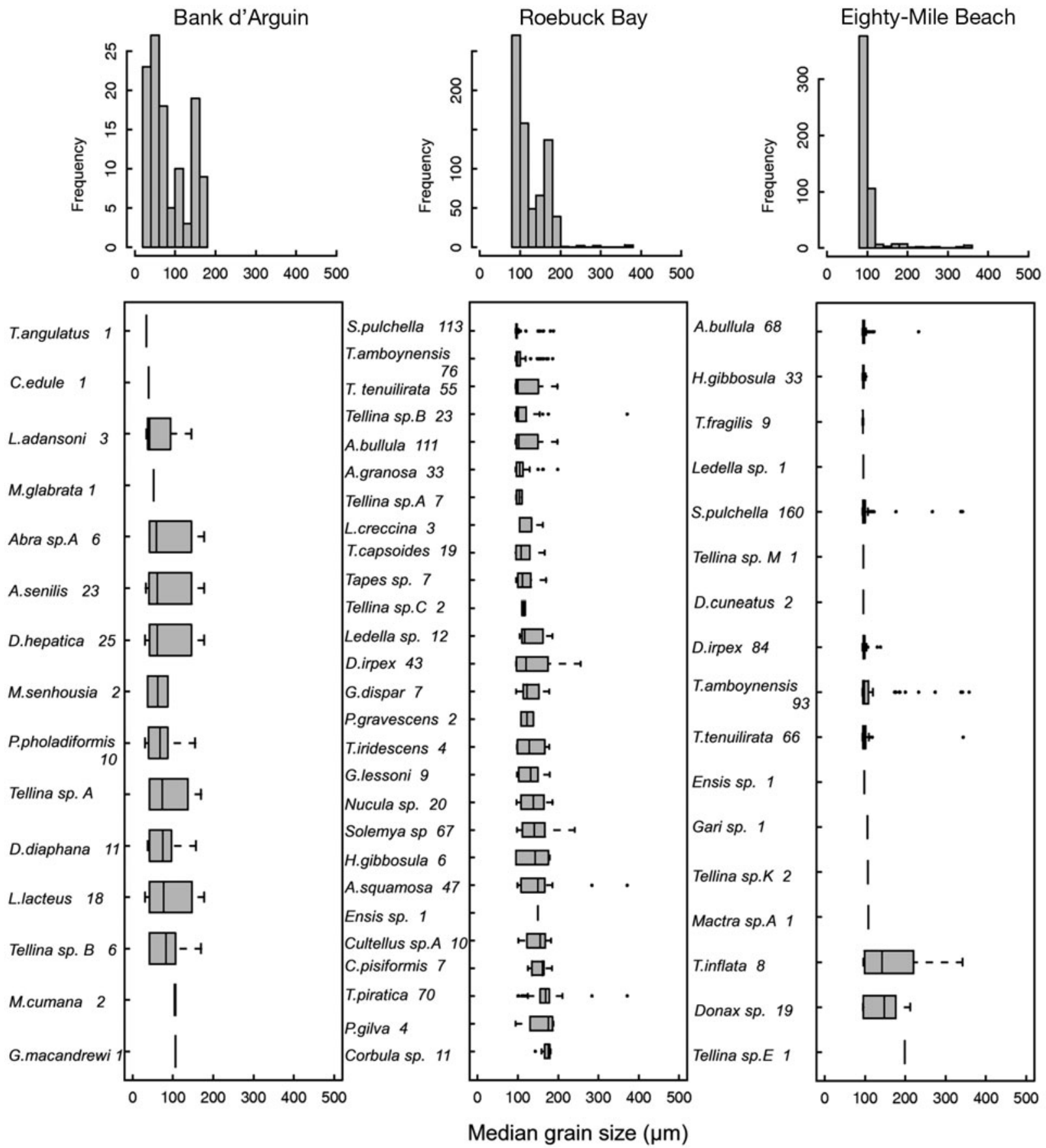

Fig. 6. Ranked boxplots of bivalve species distributions (presence data only) in the tropical intertidal systems using measured median grain size values. The name of the species and number of occurrences measured per species are shown next to each boxplot. The histograms above the boxplots represent the frequency of median grain size values occurring in each system. Full names of the species are given in Appendix 2 (www.int-res.com/articles/suppl/m373p025_app.pdf)

Wadden Sea and The Wash. The high point diversity at the Banc d'Arguin can be explained by the larger surface area of sediment sampled per sample point. The interquartile ranges representing the occurrences of species across the sediment gradient of each system reinforced our regression results and showed that spe- cies shared a large degree of distributional overlap in each system. Distributional overlap was most notable at the tropical system of Roebuck Bay.

Distributional overlap, as shown by both bivalve point diversity and the interquartile ranges of bivalve distributions, could suggest that there are physical 
and/or biological factors that limit use of the full range of available sediments within a system, e.g. large bioturbating species can reduce benthic diversity in sedimentary systems (Lohrer et al. 2008). Alternatively, the preference for fine-grained sediments might indicate a favourable habitat, e.g. due to higher food concentrations (Lopez \& Levinton 1987), or due to species working their own environment and creating positive feedback loops that provide food and create habitat space for other species (Bertness \& Leonard 1997, Bruno et al. 2003, Coco et al. 2006, Thrush et al. 2008); single bivalve species can have a positive effect on species diversity in a patch (Norling \& Kautsky 2007). Finally, this emergent pattern could reflect mediated effects, i.e. factors that are system dependent, across systems (Thrush et al. 2005, Hewitt et al. 2007).

Surprisingly, despite expectations based on bivalve life-history strategies (see references in 'Introduction'), we found that bivalve diversity and total benthic diversity were not associated with habitat heterogeneity across 9 tidal flat systems. Instead, bivalve species shared a large degree of distributional overlap in finegrained, 'complex' sediments. These results show that small-scale patterns can reflect large-scale patterns, i.e. distributional overlap at smaller spatial scales and the lack of correlation between bivalve diversity and habitat heterogeneity at larger spatial scales show that the coexistence between bivalve species in diverse tidal flats is not associated with increased sediment heterogeneity.

Acknowledgements. For help in the field we thank many volunteers. In addition, we thank W. Boer, A. Evers, G. Kerluguen, A. Garbutt, A. Schrijver and M. Meegdes for help with the sediment analyses. For logistical support in Australia we thank the Stoat family of Anna Plains Station, Broome Bird Observatory, Department of Environment and Conservation, N. Burrows, J. Lane and K. Morris of Science Division, A. Grosse, M. Lapwood, K. Miller of West Kimberley District, Lotteries Commission through the Gordon Reid Foundation, Landscope Expeditions, Wallis Drilling, Landscope Visa Grants, Department of Main Roads, Curtin University and T. Costello. Expeditions in Australia were funded by Lotteries, Wallis Drilling, CALM and Landscope Expeditions. Research on mudflats in Germany was facilitated by a MAVA grant to T.P. and J.L. Some of the early benthic exploits were funded by a PIONIER grant to T.P. from the Netherlands Organization for Scientific Research (NWO). T.J.C. was funded by an Ubbo Emmius Scholarship from the University of Groningen. We thank M. J. A. Rijkenberg, J. Drent and W. J. Wolff and 2 anonymous reviewers and the editor for very helpful comments on the manuscript.

\section{LITERATURE CITED}

Attrill MJ, Stafford R, Rowden AA (2001) Latitudinal diversity patterns in estuarine tidal flats: indications of a global cline. Ecography 24:318-324

> August PV (1983) The role of habitat complexity and heterogeneity in structuring tropical mammal communities.
Ecology 64:1495-1507

Beesley PL, Ross GJB, Wells A (1998) Mollusca: the southern synthesis, Part B. CSIRO Publishing, Melbourne

Bertness MD, Leonard GH (1997) The role of positive interactions in communities: lessons from intertidal habitats. Ecology 78:1976-1989

> Beukema JJ, Dekker R (2003) Redistribution of spat-sized Macoma balthica in the Wadden Sea in cold and mild winters. Mar Ecol Prog Ser 265:117-122

Biernbaum CK (1979) Influence of sedimentary factors on the distribution of benthic amphipods of Fishers Island Sound, Connecticut. J Exp Mar Biol Ecol 38:201-223

Bocher P, Piersma T, Dekinga A, Kraan C and others (2007) Site- and species-specific distribution patterns of molluscs at five intertidal soft-sediment areas in northwest Europe during a single winter. Mar Biol 151:577-594

Boström C, Jackson EL, Simenstad CA (2006) Seagrass landscapes and their effects on associated fauna: a review. Estuar Coast Shelf Sci 68:383-403

Bouma H, de Vries PP, Duiker JMC, Herman PMJ, Wolff WJ (2001) Migration of the bivalve Macoma balthica on a highly dynamic tidal flat in the Westerschelde estuary, The Netherlands. Mar Ecol Prog Ser 224:157-170

Bruno JF, Stachowicz JJ, Bertness MD (2003) Inclusion of facilitation into ecological theory. Trends Ecol Evol 18: 119-125

Butman CA (1987) Larval settlement of soft sediment invertebrates - the spatial scales of pattern explained by active habitat selection and the emerging role of hydrodynamical processes. Oceanogr Mar Biol Annu Rev 25: 113-165

Buurman P, Pape T, Reijneveld JA, de Jong F, van Gelder E (2001) Laser-diffraction and pipette method grain sizing of Dutch sediments: correlations for fine fractions of marine, fluvial and loess samples. Neth J Geosci 80:49-57

Clarke KR, Warwick RM (1998) A taxonomic distinctness index and its statistical properties. J Appl Ecol 35:523-531

> Coco G, Thrush SF, Green MO, Hewitt JE (2006) Feedbacks between bivalve density, flow, and suspended sediment concentration on patch stable states. Ecology 87: $2862-2870$

> Colwell RK, Coddington JA (1994) Estimating terrestrial biodiversity through extrapolation. Phil Trans R Soc Lond B 345:101-118

Colwell RK, Mao CX, Chang J (2004) Interpolating, extrapolating, and comparing incidence-based species accumulation curves. Ecology 85:2717-2727

> Compton TJ, Kentie R, Storey AW, Veltheim I, Pearson GB, Piersma T (2008) Carbon isotope signatures reveal that diet is related to the relative sizes of the gills and palps in bivalves. J Exp Mar Biol Ecol 361:104-110

Crawley MJ (2005) Statistics, an introduction using R. Wiley, Chichester

de Goeij P, Luttikhuizen PC, van der Meer J, Piersma T (2001) Facilitation on an intertidal mudflat: the effect of siphon nipping by flatfish on burying depth of the bivalve Macoma balthica. Oecologia 126:500-506

> Drent J, Luttikhuizen PC, Piersma T (2004) Morphological dynamics in the foraging apparatus of a deposit feeding marine bivalve: phenotypic plasticity and heritable effects. Funct Ecol 18:349-356

Edelaar P (2000) Phenotypic plasticity of burrowing depth in the bivalve Macoma balthica: experimental evidence and general implications. In: Harper EM, Taylor JD, Crame JA (eds) The evolutionary biology of the Bivalvia. The Geological Society of London, London, p 451-458

> Edgar GJ, Shaw C, Watson GF, Hammond LS (1994) Comparisons of species richness, size-structure and production of 
benthos in vegetated and unvegetated habitats in Western-Port, Victoria. J Exp Mar Biol Ecol 176:201-226

Etter RJ, Grassle JF (1992) Patterns of species diversity in the deep-sea as a function of sediment particle size diversity. Nature 360:576-578

Fortin MJ, Dale MRT (2005) Spatial analysis: a guide for ecologists. Cambridge University Press, Cambridge

Gray JS (1967) Substrate selection by archiannelid Protodrilus rubropharyngeus. Helgol Wiss Meeresunters 15:253-269

Gray JS (1981) The ecology of marine sediments: an introduction to the structure and function of benthic communities. Cambridge University Press, Cambridge

Hewitt JE, Thrush SE, Halliday J, Duffy C (2005) The importance of small-scale habitat structure for maintaining beta diversity. Ecology 86:1619-1626

> Hewitt JE, Thrush SF, Dayton PK, Bonsdorff E (2007) The effect of spatial and temporal heterogeneity on the design and analysis of empirical studies of scale-dependent systems. Am Nat 169:398-408

> Honkoop PJC, Pearson GB, Lavaleye MSS, Piersma T (2006) Spatial variation of the intertidal sediments and macrozoobenthic assemblages along Eighty-Mile Beach, northwestern Australia. Neth J Sea Res 55:278-291

Honkoop PJC, Berghuis EM, Holthuijsen S, Lavaleye MSS, Piersma T (2008) Molluscan assemblages of seagrasscovered and bare intertidal flats on the Banc d'Arguin, Mauritania, in relation to characteristics of sediment and organic matter. J Sea Res 60:255-263

> Huxham M, Richards M (2003) Can postlarval bivalves select sediment type during settlement? A field test with Macoma balthica (L.) and Cerastoderma edule (L.). J Exp Mar Biol Ecol 288:279-293

Konert M, van den Bergh EJ (1997) Comparison of laser grain size analysis with pipette and sieve analysis: a solution for the underestimation of the clay fraction. Sedimentology 44:523-535

Kraan C, Piersma T, Dekinga A, Koolhaas A, van der Meer J (2007) Dredging for edible cockles (Cerastoderma edule) on intertidal flats: short-term consequences of fisher patch-choice decisions for target and non-target benthic fauna. ICES J Mar Sci 64:1735-1742

Lack D (1969) The numbers of bird species on islands. Bird Study 16:193-209

Lopez GR, Levinton JS (1987) Ecology of deposit-feeding animals in marine sediments. Q Rev Biol 62:235-259

> Lohrer AM, Chiaroni LD, Hewitt JE, Thrush SF (2008) Biogenic disturbance determines invasion success in a subtidal soft-sediment system. Ecology 89:1299-1307

MacArthur RH, Wilson EO (1967) The theory of island biogeography. Princeton University Press, Princeton, NJ

McCullagh P, Nelder JA (1989) Generalized linear models. Chapman and Hall/CRC, London

Murdoch WW, Evans FC, Peterson CH (1972) Diversity and pattern in plants and insects. Ecology 53:819-829

Norling P, Kautsky N (2007) Structural and functional effects of Mytilus edulis on diversity of associated species and ecosystem functioning. Mar Ecol Prog Ser 351:163-175

Oksanen J (2007) The Vegan package: community ecology package. Documentation on the R package vegan, version 1.13. http://vegan.r-forge.r-project.org. Accessed August 2008

Orth RJ, Heck KL, Vanmontfrans J (1984) Faunal communities in seagrass beds - a review of the influence of plant structure and prey characteristics on predator prey relationships. Estuaries 7:339-350

Palmer MW (1990) The estimation of species richness by extrapolation. Ecology 71:1195-1198
Pepping M, Piersma T, Pearson GB, Lavaleye M (1999) Intertidal sediments and benthic animals of Roebuck Bay, Western Australia. Report 1999-3, NIOZ, Texel

> Pielou EC (1966) Shannons formula as a measure of specific diversity - its use and misuse. Am Nat 100:463-465

Pielou EC (1975) Ecological diversity. John Wiley, New York

Piersma T, de Goeij P, Tulp I (1993) An evaluation of intertidal feeding habitats from a shorebird perspective - towards relevant comparisons between temperate and tropical mudflats. Neth J Sea Res 31:503-512

Ricklefs RE, Schluter D (1993) Species diversity in ecological communities: historical and geographical perspectives. University of Chicago Press, Chicago, IL

- Sanders HL (1968) Marine benthic diversity: a comparative study. Am Nat 102:243-282

Sheridan P (1997) Benthos of adjacent mangrove, seagrass and non-vegetated habitats in Rookery Bay, Florida, USA. Estuar Coast Shelf Sci 44:455-469

Simpson EH (1949) Measurement of diversity. Nature 163:688

Smith EP, van Belle G (1984) Nonparametric-estimation of species richness. Biometrics 40:119-129

Snelgrove PVR, Butman CA (1994) Animal-sediment relationships revisited - cause versus effect. Oceanogr Mar Biol Annu Rev 32:111-177

Stanley SM (1970) Relation of shell form to life habits of the Bivalvia (Mollusca). The Geological Society of America, Boulder, CO

Thrush SF, Hewitt JE, Norkko A, Nicholls PE, Funnell GA, Ellis JI (2003) Habitat change in estuaries: predicting broad-scale responses of intertidal macrofauna to sediment mud content. Mar Ecol Prog Ser 263:101-112

> Thrush SF, Hewitt JE, Herman PMJ, Ysebaert T (2005) Multiscale analysis of species-environment relationships. Mar Ecol Prog Ser 302:13-26

Thrush SF, Halliday J, Hewitt JE, Lohrer AM (2008) The effects of habitat loss, fragmentation, and community homogenization on resilience in estuaries. Ecol Appl 18: 12-21

Ugland KI, Gray JS, Ellingsen KE (2003) The species-accumulation curve and estimation of species richness. J Anim Ecol 72:888-897

> van der Meer J (1991) Exploring macrobenthos environment relationship by canonical correlation analysis. J Exp Mar Biol Ecol 148:105-120

van Gils JA, Piersma T, Dekinga A, Spaans B, Kraan C (2006) Shellfish dredging pushes a flexible avian top predator out of a marine protected area. PLoS Biol 4:2399-2404

Ward JE, Shumway SE (2004) Separating the grain from the chaff: particle selection in suspension- and depositfeeding bivalves. J Exp Mar Biol Ecol 300:83-130

Whitlatch RB (1981) Animal-sediment relationships in intertidal marine benthic habitats: some determinants of deposit-feeding species diversity. J Exp Mar Biol Ecol 53: 31-45

- Whittaker RH (1972) Evolution and measurement of species diversity. Taxon 21:213-251

Wolff WJ (1973) The estuary as a habitat. An analysis of data on the soft-bottom macrofauna of the estuarine area of the rivers Rhine, Meuse, and Scheldt. Zool Verh 126:3-242

Wolff WJ, Smit CJ (1990) The Banc d'Arguin, Mauritania, as an environment for coastal birds. Ardea 78:17-38

> Wu RSS, Shin PKS (1997) Sediment characteristics and colonization of soft-bottom benthos: a field manipulation experiment. Mar Biol 128:475-487

> Ysebaert T, Meire P, Herman PMJ, Verbeek H (2002) Macrobenthic species response surfaces along estuarine gradients: prediction by logistic regression. Mar Ecol Prog Ser 225:79-95

Submitted: November 7, 2007; Accepted: September 3, 2008

Proofs received from author(s): December 8, 2008 